\title{
QUISTE HIDATIDICO CARDIOPERICARDICO: PRESENTACION DE DOS CASOS CLINICOS
}

\author{
Drs. Roberto Miranda L. (1), Adriana Merchak A. (2), TMs. Pilar Ferrier, Alex Villarroel, Oscar Edding.
}

1. Servicio de Tomografía Computada Hospital FACH

2. Servicio de Radiología Hospital Luis Calvo Mackenna

\begin{abstract}
Hydatidic cyst of the heart and pericardium are an uncommon lesion that usually develops in the left ventricle and the clinical signs and symptoms are nonspecific and highly variable, may be difficult to diagnose. In this report we describe two unusual case of cardiac, pericardial and pulmonary hydatid cyst. It was demonstrated by using helical computed tomography and serological test for echinococcosis. Key Words: Cardiac hydatidic cyst, Helical computed tomography.
\end{abstract}

Resumen: La hidatidosis es una enfermedad endémica en Chile. Se puede desarrollar en cualquier parte del cuerpo. Los órganos más frecuentemente afectados son el hígado en el adulto y el pulmón en los niños. La hidatidosis en localizaciones no habituales puede causar problemas diagnósticos. Revisamos la presentación de dos casos de hidatidosis cardio-pericárdica y pulmonar diagnosticadas con tomografía computada helicoidal, complementada con resonancia magnética en uno de ellos y confirmada con serología positiva para el equinococo y cirugía.

Palabras claves: Quiste hidatídico cardiopericárdico, Tomografía helicoidal.

\section{Introducción}

La enfermedad por quiste hidatídico $(\mathrm{QH})$ es causada principalmente por el estado quístico del parásito Echinococcus Granulosus y menos frecuentemente por el Echinococcus Alveolaris, es de alta prevalencia en la parte Sur de América, especialmente donde existe crianza de ganado ovino ${ }^{(1,2)}$. La forma de gusano adulto vive en el intestino del huésped definitivo, comúnmente el perro, y no mide más

Miranda R. y cols. Quiste hidatídico cardiopericárdico: Presentación de dos casos clínicos. Rev Chil Radiol 2002; 8: 123 - 126

Correspondencia: Dr. Roberto Miranda L. rmradiologia@yahoo.com de $5 \mathrm{~mm}$. Las ovejas y el hombre son huéspedes intermedios, donde se desarrolla el estado larval quístico. Al hombre llega por contacto con el huésped definitivo, que elimina los huevos por las heces, o por aguas o verduras contaminadas ${ }^{(1)}$.

Presentamos los hallazgos de dos casos de QH cardiopericárdico diagnosticados con tomografía computada helicoidal $(\mathrm{TCH})$, con pruebas serológicas positivas y comprobados con cirugía.

\section{Casos clínicos}

Caso 1: Paciente de 33 años, sexo masculino, que consulta por dolor torácico leve y moderada disnea. Se realiza radiografía $(\mathrm{Rx})$ de tórax que muestra varios nódulos pulmonares redondeados, leve borramiento del ángulo costofrénico derecho y una gran cardiomegalia polilobulada (Figura 1). La ecocardiografía reveló la presencia de masas trabeculadas, complejas, de aspecto quístico y una masa móvil en ambas aurículas. Se plantea la posibilidad de un compromiso neoplásico secundario, motivo por el cual se solicita $\mathrm{TCH}$.

La TCH muestra la presencia de múltiples lesiones quísticas pulmonares bilaterales de hasta $3 \mathrm{~cm}$ de diámetro (Figura 2), además de un extenso compromiso de todos los compartimentos pericárdicos y de ambas aurículas. Las lesiones tienen una pared bien definida, algunas con tabiques que aumentan su densidad con el uso de contraste (Figura 3). Se plantea como diagnóstico la posibilidad de una hidatidosis cardiopericárdica y pulmonar, la que se confirma con serología específica para QH y con los hallazgos quirúrgicos. Se deja en tratamiento médico con Abendazol.

Caso 2: El segundo caso es el de un niño de 7 años, eutrófico, derivado desde Coyhaique en donde presentó un cuadro brusco de dolor abdominal con colapso cardiorrespiratorio y pérdida de conciencia, destacando a su ingreso en la Rx de tórax una cardiomegalia (Figura 4) y un derrame pericárdico en la ecocardiografía. Se recupera de su compromi- 

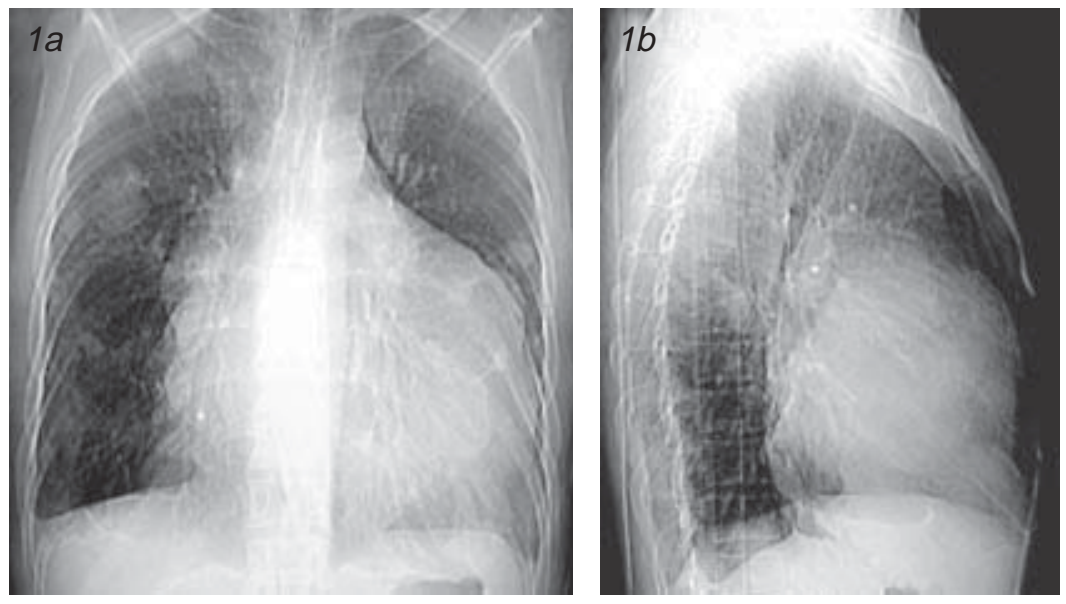

Figura 1 a,b. Caso 1. a. Rx frontal. b. lateral de tórax demostrando cardiomegalia polilobulada y nódulos pulmonares.
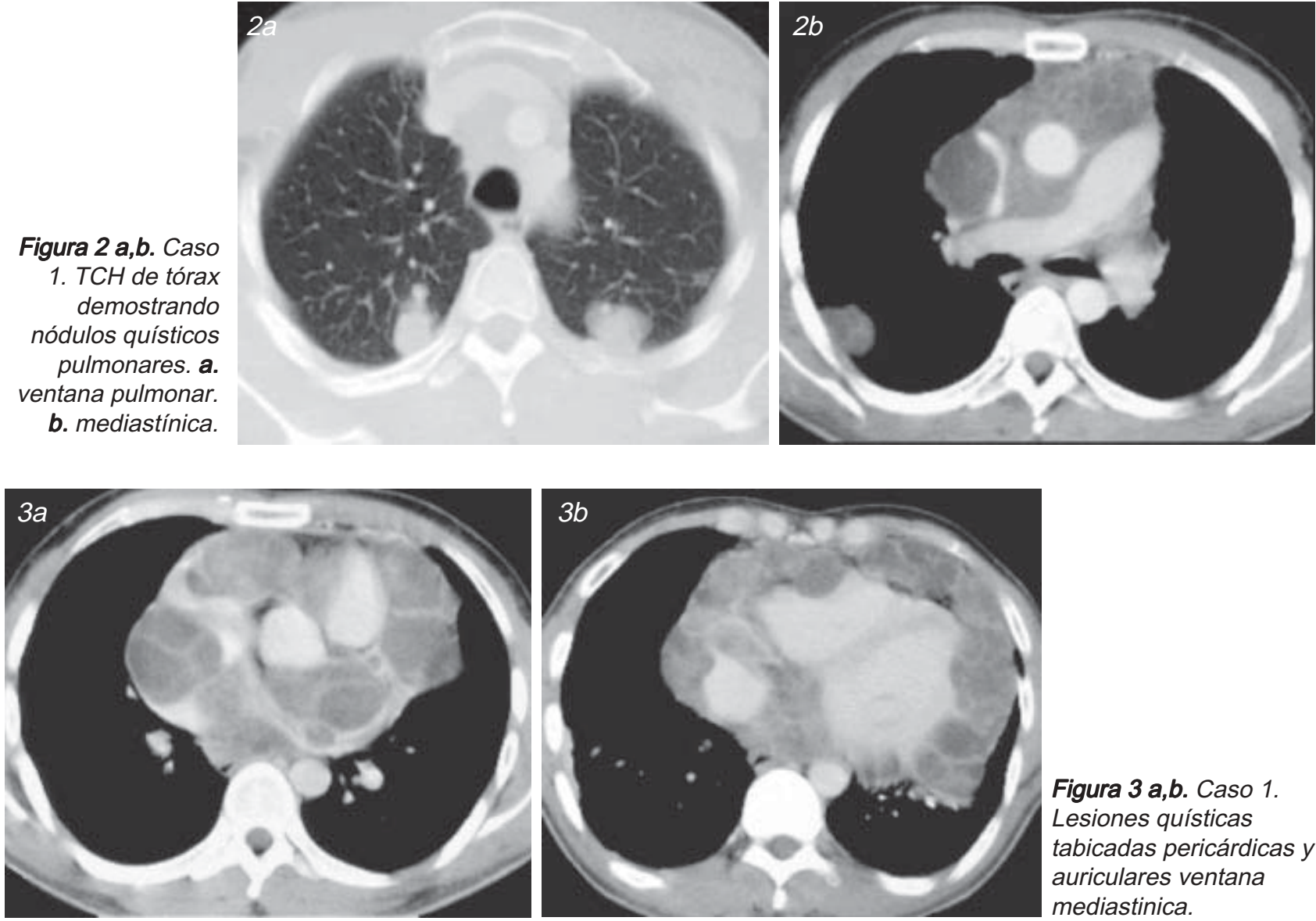

Figura 3 a,b. Caso 1. Lesiones quísticas tabicadas pericárdicas $y$ auriculares ventana mediastinica.

so general agudo pero el electrocardiograma (ECG) persiste alterado por lo que es derivado a Santiago. Se realiza nuevo ecocardiograma que revela la presencia de al menos dos masas quísticas, de $4.5 \mathrm{~cm}$ en la pared anterior del ventrículo derecho y de 4 $\mathrm{cm}$. en la pared posterior del ventrículo izquierdo. Se plantea la posibilidad de una hidatidosis y se solicita $\mathrm{TCH}$ y resonancia magnética (RM).

La tomografía muestra la presencia de múltiples quistes pericárdicos principalmente en el receso subaórtico y diafragmático, de pared bien definida, tabicados, sin claro compromiso de la pared cardiaca (Figura 5). La RM muestra quistes de localización pericárdica subaórtica y yuxtadiafragmáticos, sin derrame pericárdico, con adelgazamiento de la punta del ventrículo derecho, con una clara pared hipointensa (Figura 6).

Las pruebas serológicas fueron positivas para $\mathrm{QH}$. También fue operado y dejado en tratamiento con abendazol.

\section{Discusión}

El QH se puede desarrollar casi en cualquier parte del cuerpo. En el adulto el hígado es el órgano 
blanco más frecuente (59-75\%), seguido por el pulmón (15-27\%). El resto del cuerpo se ve afectado en aproximadamente un 10\%: riñón 3\%, hueso 1-4\% y cerebro $1-2 \%$. Sitios como el bazo, páncreas, músculos y corazón son afectados muy rara vez. El compromiso puede ser por quistes únicos o múltiples, uni o multilobulados(3).

En la edad pediátrica el sitio más comúnmente afectado es el pulmón, seguido por el hígado. Otros
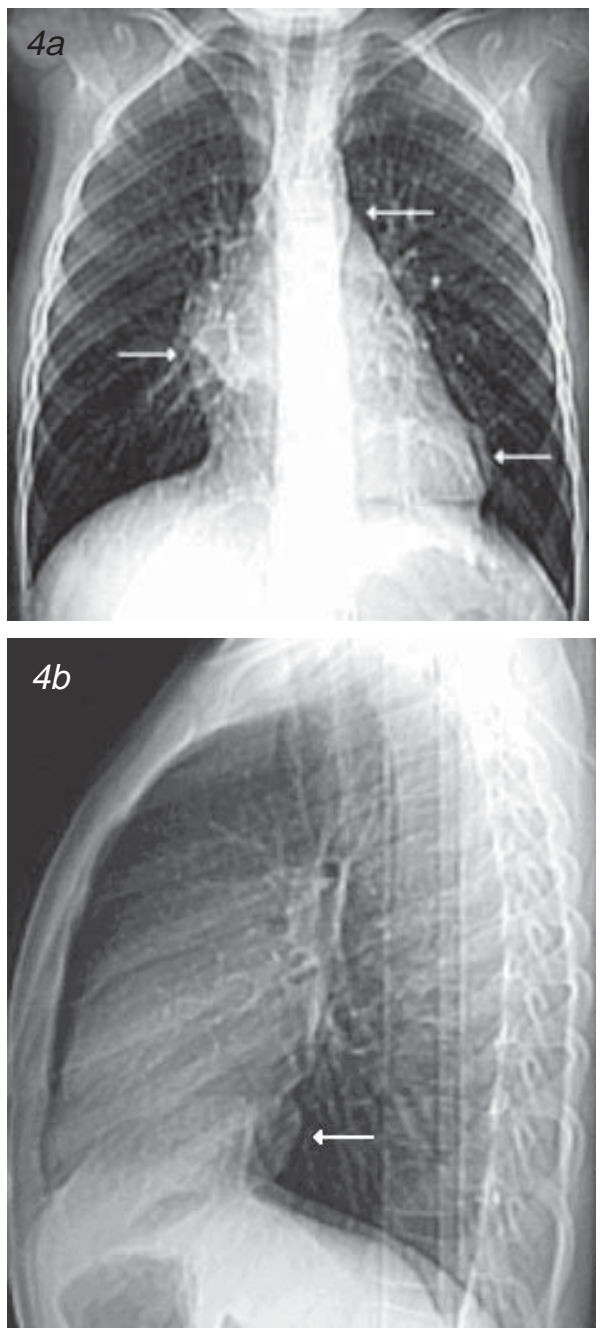

Figura 4 a,b.

Caso 2. $R x$

de tórax. a. frontal. $b$.

lateral con lobula-ciones de la silueta cardiaca (flechas).

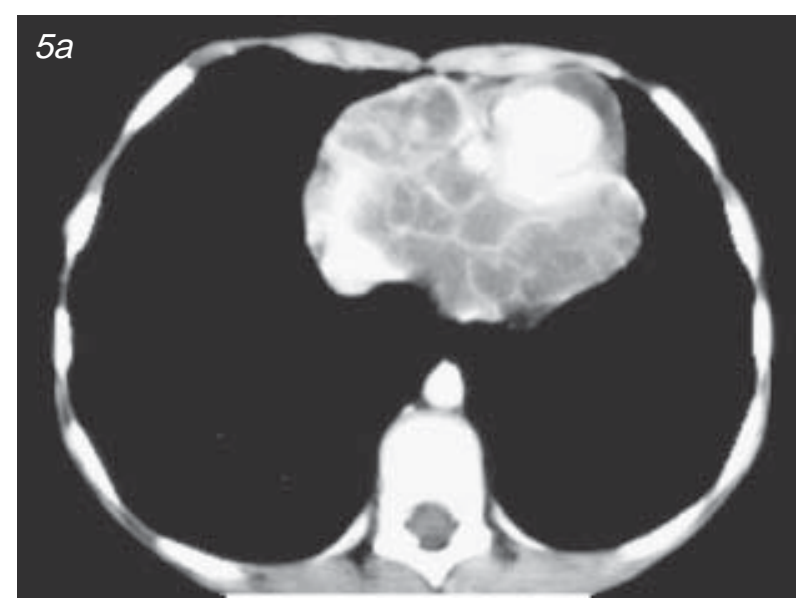

sitios posibles son los riñones, corazón, órbita, cuello y hueso; muy rara vez afecta al cerebro(2). Muchas veces la enfermedad es adquirida en la edad pediátrica pero no se diagnostica hasta la tercera o cuarta década de la vida. Aproximadamente el 10$25 \%$ de los casos se manifiesta en la niñez y la mayoría son asintomáticos; cuando dan síntomas, generalmente es por rotura e infección secundaria. La sintomatología depende fundamentalmente del lento crecimiento del quiste. Su localización en sitios infrecuentes puede causar problemas en el diagnóstico diferencial.

El quiste está formado por tres capas $^{(4)}$, la externa o periquiste compuesta por células del huésped modificadas y células inflamatorias; la media que es acelular y la capa interna o endoquiste que es la membrana germinal donde se desarrollan los escólices o estado larval.

Se clasifican según su aspecto anátomo-patológico en 3 tipos:

Tipo I que es una estructura quística pura llena de líquido, con tres capas: el periquiste, la membrana media acelular y el endoquiste. El líquido es un trasudado antigénico.

Tipo I/ es aquel en que se desarrollan vesículas hijas en el interior del quiste

Tipo III que es el QH muerto, calcificado y biológicamente inerte.

El QH cardiopericárdico es raro, con una incidencia aproximada de $0.02-2 \%$ de todos los $\operatorname{casos}^{(3-}$ 8) y puede tener consecuencias fatales. La invasión del corazón ocurre a través de la circulación coronaria o por rotura de un quiste pulmonar. El embrión se fija al miocardio y en 1 a 5 años forma el quiste adulto. La rotura a pericardio puede ocasionar taponamiento y muerte, derrame pericárdico o siembra de múltiples quistes ${ }^{(6)}$.

Los quistes se desarrollan principalmente en el miocardio. El $60 \%$ en la pared del ventrículo izquierdo, $10 \%$ en el derecho, $6 \%$ en aurícula izquierda, $7 \%$ en el pericardio y $7-10 \%$ en el tabique. La sintomatología es inespecífica e incluso puede estar

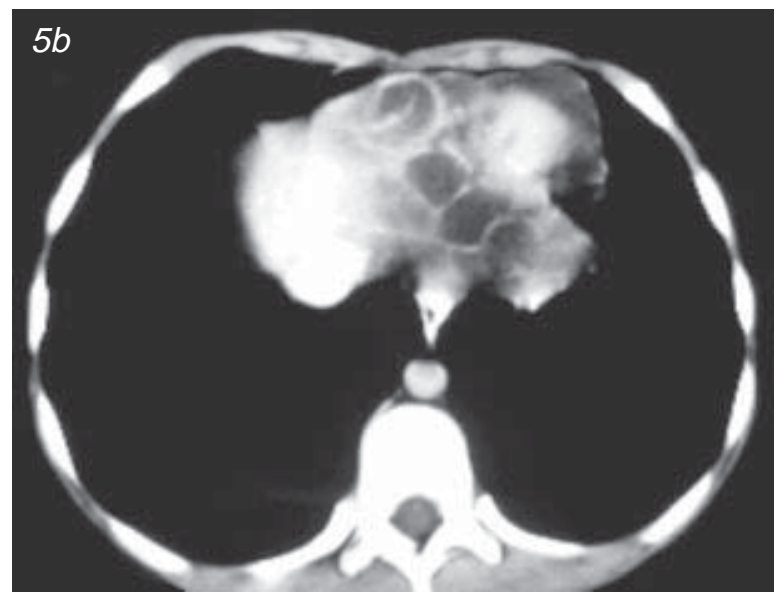

Figura 5 a,b. Caso 2. TCH con ventana mediastínica, muestra lesiones quísticas múltiples pericárdicas. 

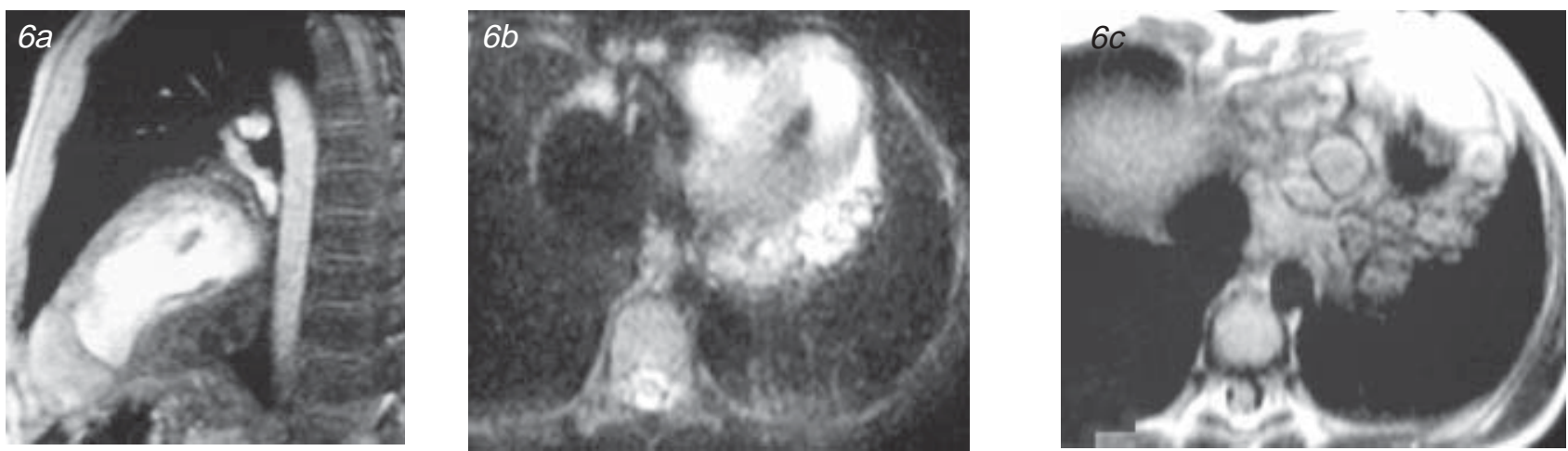

Figura 6 a,b,c. Caso 2. RM plano sagital FLASH (a) y axial HASTE (b,c), que muestran imágenes de comportamiento quístico pericárdicas.

ausente; puede existir dolor torácico, disnea de esfuerzo, palpitaciones, fiebre, alteraciones en la conducción eléctrica. La complicación más importante es la rotura que puede desencadenar un shock anafiláctico o un taponamiento cardíaco; también puede dar embolización pulmonar o sistémica.

La eosinofilia se presenta en el $20-40 \%$ (1) asociada generalmente a rotura reciente. Por lo tanto, dada la inespecificidad de la signo-sintomatología del QH cardiopericárdico, establecer el diagnóstico clínico de esta enfermedad se hace difícil.

Con el uso de la ecocardiografía, la TCH y la $\mathrm{RM}^{(3,7,9)}$ el diagnóstico del $\mathrm{QH}$ se ha facilitado. La radiografía de tórax puede mostrar una lobulación del contorno cardíaco (Figuras 1 y 4), calcificación en anillo o imagen de aneurisma ventricular; puede existir compromiso pulmonar simultáneo. La ecocardiografía puede dar información de la naturaleza quística de la masa y su relación con las cavidades cardíacas; no permite diferenciar un $\mathrm{QH}$ de un quiste pericárdico congénito(6,8).

$\mathrm{La} \mathrm{TCH}{ }^{(10)}$ permite una adecuada caracterización de la naturaleza quística de las lesiones, define el aspecto de su pared y su localización pericárdica o en las cavidades cardíacas; además permite evaluar la presencia de lesiones en otros órganos como pulmón o hígado (Figuras 2,3 y 5). En la actualidad, dada la rápida adquisición de las imágenes con los equipos helicoidales, los artefactos por movimientos (respiratorios o de latidos) se minimizan, obteniéndose una excelente definición de contraste, de las densidades de estas lesiones y de la ubicación de las mismas, permitiendo incluso gracias a la resolución isotrópica, una adecuada evaluación multiplanar. En nuestros dos casos la $\mathrm{TCH}$ fue suficiente en la orientación diagnóstica exacta.

La $\mathrm{RM}^{(7,9)}$ también muestra la naturaleza quística de las lesiones que son hipointensas en T1 e hiperintensas en T2; con un típico anillo hipointenso de la pared (Figura 6). Tiene como ventajas demostrar el compromiso de la pared miocárdica, ver la función cardiaca y el no uso de contraste. El tiempo de examen y su menor disponibilidad no la hacen un examen de primera elección especialmente si con- tamos con TCH. Sin embargo, la RM es el método de elección en localizaciones como el cerebro o esqueleto(3).

En el diagnóstico diferencial debe considerarse una variedad de tumores del corazón como los mixomas, aneurismas del seno de Valsalva, aneurisma de la pared del ventrículo izquierdo y los quistes congénitos del pericardio. Sin embargo, la apariencia morfológica de una lesión quística con una pared bien definida y vascularizada, multivesicular, ayudan a establecer el diagnóstico. Se debe también considerar el antecedente de la procedencia del paciente desde zonas endémicas. Las pruebas serológicas también son de ayuda pero pueden ser negativas hasta en un $57 \%$ de los pacientes, principalmente en niños.

La cirugía es el tratamiento de elección pero, algunas veces por la multiplicidad de lesiones o adherencia con estructuras vitales se hace difícil la remoción total. El tratamiento médico asociado es generalmente de regla.

\section{Bibliografía}

1. Beggs I. The radiology of hydatid disease. AJR 1985; 145:639-648

2. Haliloglu M, Saatci I. Spectrum of imaging findings in pediatric hydatid disease. AJR 1997; 169:1627-1631.

3. Engin G, Acunas B. Hydatid disease with unusual localization. Eur. Radiol. 2000; 10: 1904-1912.

4. Dahniya M., Hanna R. The imaging appearances of hydatid disease at some unusual sites. $\mathrm{Br} \mathrm{J}$ Radiol 2001; 74:283-289.

5. Birincioglu C. A clinical dilemma: cardiac and pericardiac echinococcosis. Ann Thorac Surg 1999; 68:1290-1294.

6. Kurtoglu N. Interventricular septal hydatid cyst. Echocardiography 2000; 17:693-695.

7. Cantoni S. Hydatid cyst of the interventricular septum of the heart: MR findings. AJR1993; 161:753-754.

8. Bashour T. Echinococcosis of the heart: clinical and echocardiographic features in 19 patients. Am Heart Journal 1996; 132: 1028-1030.

9. Manisali M. The role of MR imaging in cardiac echinococcosis. AJR 1997; 168:282-283.

10. Reiser MF, Takahashi M, Modic M. Multislice CT. Medical Radiology. Springer 2001. 